\title{
EL ACUERDO MERCOSUR-UE: LOS SECTORES PROMOTORES EN BRASIL Y LOS DESAFÍOS ACTUALES PARA LA INTEGRACIÓN
}

\section{MERCOSUR-EU AGREEMENT: PROMOTERS SECTORS IN BRAZIL AND CURRENT CHALLENGES FOR INTEGRATION}

\author{
María Cecilia Míguez* \\ Agustín Crivelli**
}

\begin{abstract}
RESUMEN
Este artículo propone analizar en profundidad, las razones por las cuales actualmente Brasil lidera la reanudación de las negociaciones del acuerdo birregional Unión EuropeaMercosur; así como conocer los sectores internos y corporaciones económicas que promueven ese vínculo, la posición de las oficinas de gobierno y finalmente, las tensiones que se presentan en la estrategia internacional de Brasil y el proceso de integración regional en el Cono Sur.
\end{abstract}

PALABRAS CLAVE: BRASIL * MERCOSUR * UNIÓN EUROPEA * ACUERDOS ECONÓMICOS * INTEGRACIÓN REGIONAL * EMPRESAS COMERCIALES

\section{ABSTRACT}

This article proposed to analyze in depth the reasons that Brazil currently leads the resumption of negotiations between Mercosur and European Union. Furthermore, in order to show the domestic sectors and economic corporations that promote this association, the position of the government offices and finally, the stresses present in Brazil's international strategy and the process of regional integration in South America.

KEYWORDS: BRAZIL * MERCOSUR * EUROPEAN UNION * ECONOMIC AGREEMENTS * REGIONAL INTEGRATION * COMMERCIAL ENTERPRISES

\footnotetext{
* Universidad de Buenos Aires e Instituto de Estudios Históricos, Económicos, Sociales e Internacionales del Consejo Nacional de Investigaciones Científicas y Técnicas (IDEHESI -CONICET), Argentina. mmccmiguez@gmail.com

** Universidad de Buenos Aires e Instituto de Estudios Históricos, Económicos, Sociales e Internacionales (IDEHESI), Argentina. crivelli@gmail.com
} 


\section{INTRODUCCIÓN}

En el año 2010, se reactivaron las negociaciones entre la Unión Europea (UE) y el Mercosur, con la finalidad de firmar un acuerdo interbloque que incluyera no solamente aspectos comerciales, sino también de inversiones $y$ aquellos considerados омс Plus ${ }^{1}$, ya que en el año 2004, se había paralizado este proceso. El proyecto de un acuerdo birregional Mercosur-UE se había lanzado en ocasión de la I Cumbre ALcuE realizada en Río de Janeiro, en junio de 1999. Se trató desde el comienzo de una negociación difícil, en tanto puso rápidamente en evidencia, las posiciones de posibles sectores afectados, en especial el sector agrícola de varios países de la uE $y$ sectores industriales de países del Mercosur.

En ese momento, el Mercosur era atractivo en función de todas las inversiones europeas realizadas en la región -especialmente en Argentina y Brasil- en el marco de la etapa de apertura neoliberal y constituía un área específica de disputa respecto a las intenciones de los Estados Unidos de conformar una zona de libre comercio continental (Área de Libre Comercio de las Américas-ALCA). El posterior fracaso de este proyecto de los Estados Unidos, fue uno de los factores que puede explicar el estancamiento de las negociaciones. No obstante, la parálisis de 2004, se vinculó principalmente con el fracaso de la V Ronda de Doha, celebrada en Cancún en 2003.

En esa oportunidad, Brasil acompañado por Argentina, defendió férreamente frente al G-202, el acceso pleno a los mercados agrícolas de los países ricos y por lo tanto, la eliminación

1 La expresión "OMC Plus" es un concepto técnico-coloquial que hace referencia a los acuerdos comerciales que en algunas disciplinas establecen un mayor grado de liberalización que los compromisos establecidos en el sistema multilateral de comercio acordado en el ámbito de la OMC. En general incluyen los llamados Temas de Singapur: inversiones, compras gubernamentales, facilidades al comercio y políticas de competencia.

2 Los países que conforman el G- 20 son: Al G-8 Alemania, Canadá, Estados Unidos, Francia, Italia, Japón, Reino Unido, Rusia, Arabia Saudita, Argentina, Australia, Brasil, China, Corea del Sur, India, Indonesia, México, Sudáfrica, Turquía y la Unión Europea en su conjunto. de aranceles y subsidios, así como, la reducción de barreras tarifarias y no tarifarias. En esa ocasión también reiteró su defensa de las políticas proteccionistas para los bienes manufacturados. Junto con los demás países en desarrollo $y$ en desacuerdo con las potencias - en especial la uE- Brasil se opuso enérgicamente a que se ampliara la agenda de la Organización Mundial del Comercio (омс) a temas como la regulación de los estándares laborales y medioambientales, la política de defensa de la competencia, la de compras públicas o la de inversiones (омc Plus). En el período posterior a 2003, estancadas las negociaciones referidas al acuerdo, continuaron las denuncias de Brasil contra la ue ante el tribunal de resolución de diferencias de la omc, donde obtuvo resultados positivos en sus reclamos sobre la reducción de los subsidios de la uE a la producción de la banana, el azúcar y el pollo.

En 2010, las consecuencias de la crisis económica que todavía atraviesa el continente europeo y la fuerte presencia de China en la región sudamericana, contribuyeron al renovado interés de la Unión Europea durante la vI Cumbre uE-Mercosur, celebrada en Madrid. Europa percibió correctamente a las empresas chinas como competidoras, especialmente en relación con las inversiones que demandará el futuro crecimiento económico del Brasil, en producción de hidrocarburos, en el transporte y la logística; en la siderurgia y también en el sector de automoción.

Por otro lado, desde la perspectiva brasileña, también pueden señalarse razones para el renovado impulso, entre las que se encuentran los acuerdos que la ue firmó con Perú y Colombia, el consiguiente temor al desplazamiento de ventajas competitivas, el anuncio de la firma de un tratado de libre comercio uE-India, país con el que Brasil compite en rubros como agricultura, textiles, vestimenta y automoción (Peña, 2010) y el fin del Sistema General de Preferencias.

En el presente artículo, se analizarán las razones por las cuales Brasil lidera la reanudación de las negociaciones dentro del Mercosur; así como conocer los sectores internos y corporaciones económicas que promueven ese vínculo, la posición de las oficinas de gobierno y 
finalmente, las tensiones que se presentan en la estrategia internacional de Brasil.

\section{LA NEGOCIACIÓN ACTUAL MERCOSUR-UE}

En el contexto de la actual profundización de la crisis económica que afecta a gran parte del continente, la ue está especialmente interesada en la promoción de las relaciones de libre comercio ${ }^{3}$. En el caso del acuerdo uEMercosur, siguiendo la lógica actual de las negociaciones de la uE con los países de la región, se trata de un acuerdo que va más allá de lo comercial y de las obligaciones de la omc, puesto que abarcaría servicios (aún no liberalizados en Brasil), inversión, adquisición pública de bienes y servicios, cláusulas de comercio y desarrollo sostenible, y protección de derechos de propiedad intelectual $y$ las denominaciones de origen.
Además, agrega un acuerdo especial sobre medidas sanitarias y fitosanitarias, así como, el establecimiento de un mecanismo vinculante para la resolución de disputas originadas en problemas comerciales. En cuanto a las posiciones divergentes de los países de la ue, así como, los sectores industriales de Alemania y su gobierno, los principales impulsores del acuerdo son los agricultores franceses y ganaderos españoles, quienes se han mostrado más reticentes a la apertura de las importaciones de productos agropecuarios provenientes del Mercosur.

En la última década, el peso del Mercosur como destino de las exportaciones europeas se incrementó un 43,4\% (pasando de 2,12\% a $3,04 \%)$, mientras que el peso de las compras europeas desde el bloque sudamericano en el total importado por la uE, se mantuvo prácticamente constante durante el período.

\section{GRÁFICO 1 \\ UE: PARTICIPACIÓN DEL MERCOSUR EN EL COMERCIO EXTERIOR TOTAL EXTRAZONA}

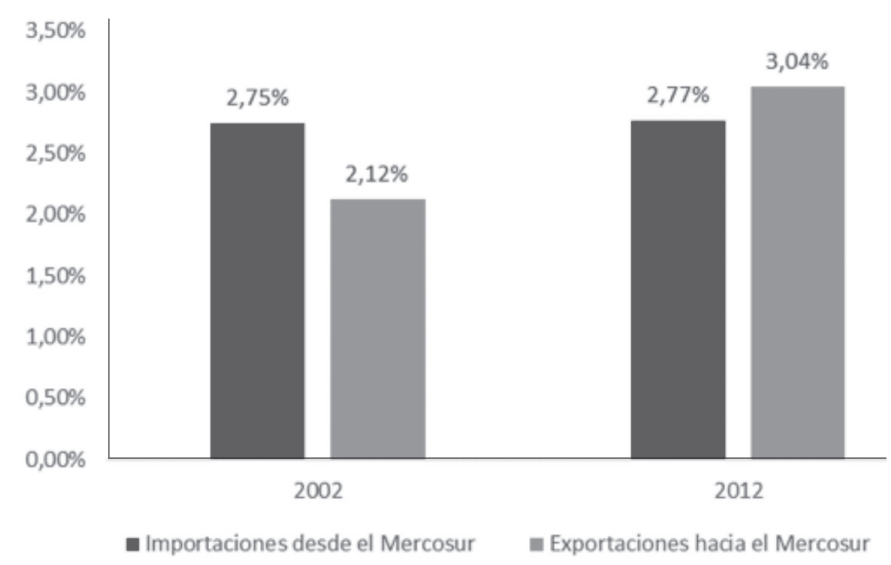

Fuente: Elaboración propia a partir de datos de Eurostat.

3 Acuerdos de libre comercio firmados: Singapur (en estado de ratificación por los parlamentos), Costa Rica, El Salvador, Guatemala, Honduras, Nicaragua y Panamá (en estado de ratificación por los parlamentos), Colombia (le falta un debate para ser aprobado por el parlamento colombiano), Perú, Corea del Sur (con carácter provisional), Montenegro, Serbia, Albania, Bosnia, Argelia, Croacia, Egipto, República de Macedonia,
Chile, Líbano, Jordania, Sudáfrica, Israel, México, Andorra, San Marino, Turquía, Palestina, Islas Faroe y Túnez.

Acuerdos de libre comercio en negociación: Mercosur, Consejo de Cooperación de los Estados del Golfo (Arabia Saudita, Omán, Bahrein, Emiratos Árabes Unidos, Qatar y Kuwait), Malasia, Vietnam, Marruecos, Tailandia, Canadá, India, Japón y Estados Unidos. 
En el caso del Mercosur, las ventas externas de la región con destino al mercado europeo - su segundo socio comercial detrás de Asia- alcanzaron en 2011, el 23\% del total exportado por el bloque regional, mientras que las importaciones desde el bloque europeo representaron el $22,2 \%$.

\section{GRÁFICO 2 \\ MERCOSUR: INTERCAMBIO COMERCIAL EXTRAZONA}

EXPORTACIONES

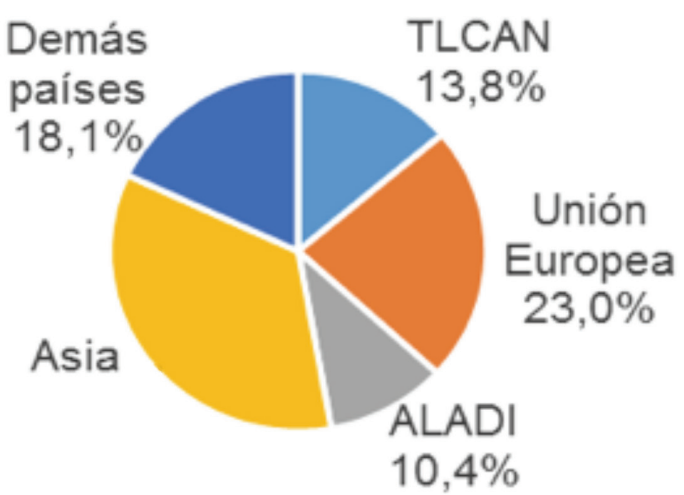

IMPORTACIONES

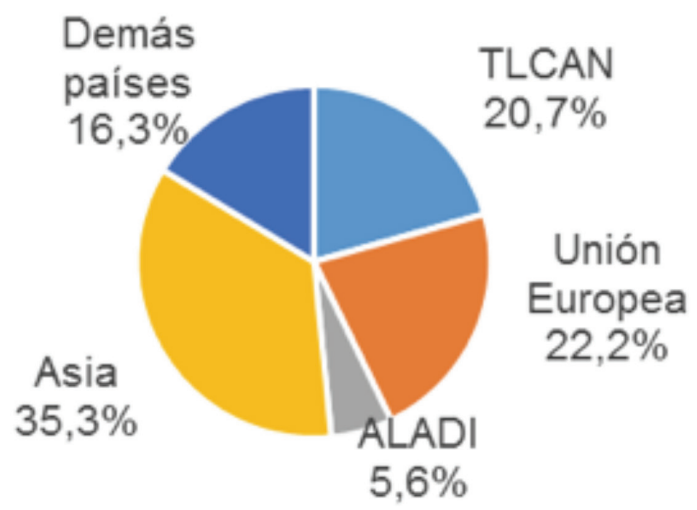

Fuente: Elaboración propia a partir de datos de INDEC (Argentina), SECEX-MDIC (Brasil), BCP (Paraguay) y BCU (Uruguay).

El comercio exterior entre las dos regiones muestra un claro patrón Norte-Sur. Clasificando la composición del intercambio comercial en productos básicos (alimentos, productos energéticos y materias primas), e industriales (semimanufacturas, bienes de equipo, sector automotriz, bienes de consumo diario, manufacturas de consumo y otras mercancías).
Durante el año 2012, el 90\% de las exportaciones de la UE hacia el Mercosur fueron productos industriales (un $94,9 \%$ una década antes), mientras que el $71,7 \%$ de las ventas externas del Mercosur al mercado europeo se compone de importaciones de productos bási$\cos (67,2 \%$ en el 2002$)$.

GRÁFICO 3

EVOLUCIÓN DE LA COMPOSICIÓN SECTORIAL DEL COMERCIO MERCOSUR-UE
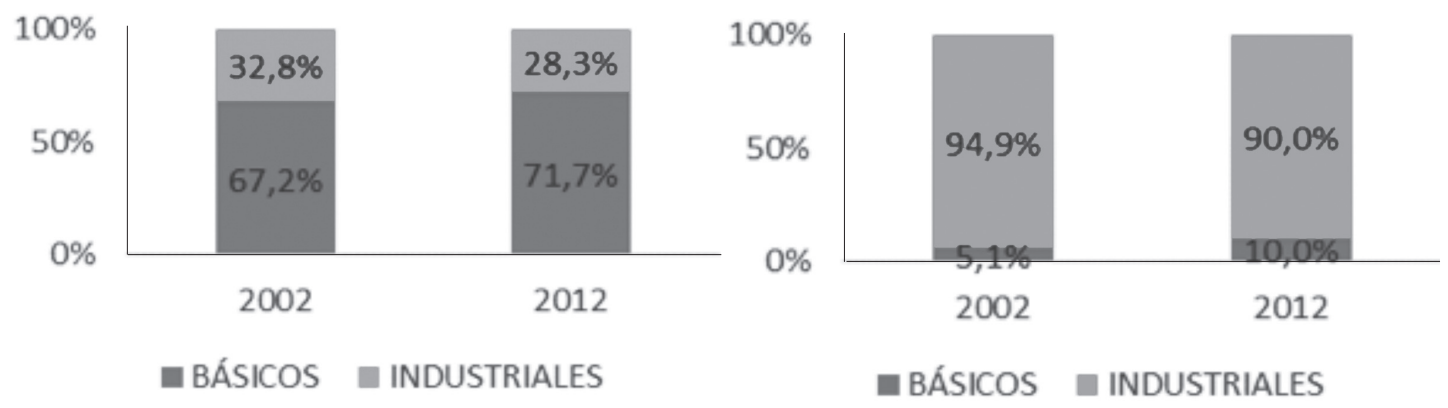

Fuente: Elaboración propia a partir de Eurostat. 
Los europeos saben que de suscribirse, este acuerdo generaría no solo un aumento del comercio interbloque, sino que conferiría a la UE una ventaja respecto de sus potencias rivales, ya que el Mercosur no tiene acuerdos preferenciales con ninguna de ellas. Además, remarcan la importancia en materia geopolítica, en tanto que el acuerdo "consolidaría la relación estratégica de la Unión Europea con Brasil, potencia emergente miembro eminente del BRIcs" (None, 2012).

En cuanto al estado actual de las negociaciones entre los bloques, el 26 y 27 de enero de este año, se realizó en Santiago de Chile, la cumbre entre la Unión Europea y la Comunidad de Estados Latinoamericanos y Caribeños (celac) donde Alemania dejó en claro su intención de avanzar en el acuerdo y también la de profundizar la alianza comercial con los países del Pacífico (México, Chile, Colombia, Perú y Costa Rica). Se trata de los mismos países que actualmente, son objeto del Tratado de Libre Comercio con los Estados Unidos, que pretende reavivar los objetivos de la sepultada ALCA. La potencia del norte se ha propuesto rubricar este año, el Acuerdo de Asocación Trans-Pacífico (TPP, según sus siglas en inglés), que busca conformar una zona de libre comercio junto con Japón, Chile, México, Perú, Canadá, Australia, Brunei, Nueva Zelanda, Singapur, Vietnam y Malasia. La Unión Europea tiene suscriptos acuerdos omc Plus con México (2000) y con Chile (2002), y sus resultados sugieren que los tratados contribuyeron a reforzar modelos económicos basados en la exportación de materias primas, aumentar las garantías a las empresas multinacionales, sacrificando el mercado interno con un consecuente aumento de la desigualdad social en función de una economía extractiva.

Unos días antes de la reunión de Santiago, en Brasilia, tuvo lugar la Cumbre Brasil-Unión Europea, donde los presidentes del Consejo Europeo, Herman Van Rompuy y de la Comisión Europea, José Manuel Barroso, junto con la presidenta Rousseff, llamaron a una "rápida" conclusión del acuerdo de libre comercio Mercosur-Unión Europea y apostaron por reforzar la relación económica bilateral. La declaración final estableció el compromiso de "evitar el proteccionismo en todas sus formas", con el fin de "favorecer un sistema de comercio multilateral abierto". Los firmantes rechazaron "todas las medidas coercitivas de carácter unilateral con efecto extraterritorial que son contrarias al derecho internacional y las normas comúnmente aceptadas de libre comercio", ya que este tipo de práctica representa una grave amenaza al multilateralismo (Comunidad de Estados Latinoamericanos y Caribeños-Cumbre Unión Europea, celac-cue, 2013).

Los diputados del parlamento europeo que buscan impulsar el acuerdo, utilizan como elemento de presión, el posible acuerdo entre Estados Unidos y la Unión Europea, que comenzó a negociarse en julio en pleno clima de tensión por los casos de espionaje que denunció el agente Richard Snowden y por la intención de Francia de excluir del pacto a la industria cultural. Es importante tener en cuenta que más allá de la viabilidad de dicho acuerdo - ya que existen reticencias importantes de ambas partes - tanto eeuu como la ue buscan utilizar el inicio de las negociaciones como elemento de presión para lograr la rápida aprobación de los tratados de libre comercio que proyectan en la región. De hecho, muchos cuestionan las posibilidades reales del gigantesco acuerdo entre las dos potencias, porque la mayoría de los líderes de la Unión Europea no quieren que las negociaciones incluyan discusiones sobre sus restricciones a cultivos modificados genéticamente $y$ otras regulaciones que mantienen productos agrícolas de Estados Unidos fuera de Europa. Por su parte, el presidente de eeuu, Barack Obama señaló que es difícil imaginar un acuerdo que no aborde esos asuntos. Poderosos cabilderos agrícolas estadounidenses harán su mejor esfuerzo para asegurarse que el Congreso rechace cualquier acuerdo que no aborde las restricciones (Butler y Melvin, 2013).

Los países del Mercosur se comprometieron a presentar antes del último trimestre de 2013, sus primeras ofertas comerciales de acceso de sus productos al mercado de la ue. Por su parte, la presidenta Cristina Fernández de Kirchner en la Cumbre de Santiago, afirmó que Argentina quiere que la nueva propuesta de ofertas comerciales contemple las asimetrías existentes entre ambos bloques (EFE, 2013). La 
afirmación refleja la preocupación por proteger en proceso de desarrollo industrial local puesto en marcha en la última década en ese país.

En el mes de marzo, en Montevideo, se realizó la primera reunión técnica entre las delegaciones de los países del Mercosur para evaluar las presentaciones nacionales con el fin de conformar una propuesta, pero no se logró avances concretos. Recientemente, Brasil parece haber dado forma a una propuesta para presentar a sus socios, mientras que en Argentina, entre el 15 de septiembre y el 15 de octubre, el gobierno impulsó a través de una serie de reuniones de trabajo, la consulta a sectores empresarios para poder formalizar la suya.

Los europeos pretenden alcanzar un porcentaje del $90 \%$ en los productos a liberalizar, mientras que la Argentina está trabajando en la franja entre el $75 \%$ y el $85 \%$. La propuesta actual de Brasil, que busca alcanzar el 85\%, por ahora deja afuera algunos productos considerados sensibles, en sectores como máquinas y equipos, electrónica, químicos, autopartes y automóviles. Por otra parte, Brasil busca garantizar la prioridad nacional para las compras públicas (Zanatta y Dantas, 2013).

Contra lo que algunos pretendían afirmar, la posición de Venezuela no constituye un obstáculo en las negociaciones, ya que ha definido que solo actuará como observadora en la presentación de propuestas, si bien forma parte del bloque y tiene la actual presidencia temporaria. La posición argentina se reiteró en un comunicado oficial del 24 de septiembre, donde afirmó el interés en la consecución de un acuerdo Mercosur-ue, que constituya una "negociación equilibrada para beneficiar ambas partes" (Portal Vermelho, 2013). Algunos empresarios del sector industrial exportador, pertenecientes a la Unión Industrial Argentina, están muy interesados, como por ejemplo, en los rubros de automóviles y alimentos; mientras otros todavía se muestran desconfiados (Guimarães, 2013). Lo cierto es que con el acuerdo de Uruguay y la no participación de Paraguay en las negociaciones, el bloque de Mercosur transita el camino del acuerdo hacia la negociación, pero aparentemente buscando proteger algunos intereses internos.

\section{LA INCIDENCIA DE LOS ACTORES/ SECTORES ECONÓMICOS Y POLÍTICOS EN LA ORIENTACIÓN DE LA POLÍTICA EXTERNA BRASILERA EN RELACIÓN CON EUROPA}

En los últimos años se ha producido un cambio respecto de la histórica formulación de la política exterior en Brasil. Ese cambio, que se hizo visible desde los años 90 y que se profundizó durante la presidencia de Lula, implica una disminución de la autonomía decisoria de Itamaraty y la incorporación de otros agentes y factores de poder, en el momento de presionar para la adopción de determinadas políticas internacionales. La creciente presión de diversos sectores domésticos que buscan proyectar sus intereses en la agenda internacional, ha impulsado la creación de secciones nacionales de coordinación por parte de la cancillería, con el objeto de fomentar el debate entre el gobierno $y$ la sociedad asuntos como el Mercosur, las relaciones con Estados Unidos y las negociaciones en la омс (Cason y Power, 2009: 7).

Por su lado, las corporaciones industriales $y$ vinculadas a los agronegocios han tenido importante participación política, aportando funcionarios a los ministerios públicos. Durante la primera presidencia de Lula da Silva, el Ministerio de Desarrollo, Industria y Comercio estaba encabezado por Luiz Fernando Furlan, presidente de la empresa alimenticia Sadia y vicepresidente de la Federación de Industrias del Estado de Sao Paulo, y el Ministerio de Agricultura, por Roberto Rodrígues, representante de la Asociación Brasileña de Agrobussines y dueño de un ingenio azucarero. Ambos se mostraron como defensores de las propuestas de liberalización, por considerarlas vitales para el crecimiento económico del país, en oposición a la política llevada adelante por el canciller Celso Amorim (Giaccaglia, 2010).

Actualmente, tanto el Ministro de Economía y Hacienda, Guido Mantega (que ocupa el cargo desde 2006), como el Ministro de Desarrollo, Industria y Comercio, Fernando Pimentel, son hombres del Partido dos Trabalhadores (рт). Sin embargo, las posiciones de este último acerca de la apertura comercial son significativas respecto del rumbo a tomar por Brasil. Pimentel está impulsando fuertemente 
el perfil exportador del país en función de las tendencias que reflejan las cuentas nacionales en el 2013.

Hay que destacar que a fines del mes de julio de 2013, se hicieron públicas las cifras del primer semestre. Según los datos oficiales, la balanza comercial de los primeros siete meses del año registró un déficit de 4,989 mil millones de dólares, mientras que en el año anterior, la balanza había presentado un superávit de 9,927 mil millones. De enero a julio de este año, las exportaciones sumaron 135,23 mil millones de dólares, con un promedio diario de 926 millones, lo que implica una caída del $4,4 \%$ frente a igual período del año 2012. Las importaciones alcanzaron un total de 140,21 mil millones, con una media de 960 millones por día, es decir, un 3,4\% mayor que entre enero $y$ julio de $2012^{4}$.

En cuanto a las corporaciones económicas industriales, justamente los sectores empresarios de la Federación de Industrias del Estado de Sao Pablo (FIEsP) y la Confederación
Nacional de la Industria (cNI) son los que promueven el intercambio más fluido con Europa, a partir de las estrechas vinculaciones que tienen especialmente con Alemania.

Como se mencionó anteriormente, los primeros días de mayo se produjo el 31er. Encuentro Empresarial Brasil-Alemania, organizado por la fiesp, la cNI y la Confederación de la Industria Alemana (BDI), en el que participaron cerca de 2000 empresarios de las dos naciones. La reunión incluyó no solo la participación de Pimentel, sino por primera vez el encuentro entre los mandatarios Rousseff y Gauck. En dicho encuentro, Pimentel propuso el acercamiento comercial entre ambos países y el avance de un acuerdo de libre comercio entre el Mercosur y la Unión Europea. Alemania es hoy el principal socio europeo de Brasil y el cuarto mayor del mundo, detrás de China, Estados Unidos y Argentina. Desde 1989, la balanza comercial fue superavitaria para los alemanes. En 2012, Brasil exportó us\$ 7300 millones e importó us\$14 200 millones.

CUADRO 1

BRASIL-ALEMANIA: EVOLUCIÓN DEL INTERCAMBIO COMERCIAL (MILES DE MILLONES DE DÓLARES)

\begin{tabular}{lccccc}
\hline & 2008 & 2009 & 2010 & 2011 & 2012 \\
\hline Exportaciones Brasileras & 8,9 & 6,2 & 8,1 & 9,0 & 7,3 \\
Variación respecto al año anterior & $22,7 \%$ & $-30,2 \%$ & $31,8 \%$ & $11,1 \%$ & $-19,5 \%$ \\
Importaciones Brasileras & 12,0 & 9,9 & 12,6 & 15,2 & 14,2 \\
Variación respecto al año anterior & $38,7 \%$ & $-17,9 \%$ & $27,2 \%$ & $20,63 \%$ & $-6,6 \%$ \\
Intercambio Comercial & 20,9 & 16,0 & 20,7 & 24,3 & 21,5 \\
Variación respecto al año anterior & $31,5 \%$ & $-23,2 \%$ & $29,0 \%$ & $17,2 \%$ & $-11,4 \%$ \\
\hline Saldo Comercial & $-3,2$ & $-3,7$ & $-4,4$ & $-6,2$ & $-6,9$ \\
\hline
\end{tabular}

Fuente: Elaboración propia a partir de los datos de la SECEX-MDIC (Brasil).

$4 \quad$ Las cifras corresponden a datos oficiales de la Secretaría de Comercio Exterior del Ministério do
Desenvolvimento, Indústria e Comércio Exterior (SECEX-MDIC). 
Allí, el ministro se defendió de las acusaciones que los países desarrollados y los partidos políticos y medios opositores, realizan respecto de su proteccionismo y afirmó: "no somos proteccionistas ni podemos serlo, sería como darnos un tiro en el propio pie. Nosotros siempre seremos grandes exportadores... Brasil sabe de su inmensa potencialidad agrícola y mineral, sabe de su responsabilidad en el concierto mundial como abastecedor de recursos que serán crecientemente demandados y que son escasos" (Darlan, 2013). Al igual que en el caso de las relaciones con los Estados Unidos, Brasil busca avanzar en todas aquellas áreas no comerciales, es decir, lo que no depende de la posición del bloque Europeo ni del Mercosur: acuerdos de inversiones, cooperación tecnológica y acuerdos para evitar doble tributación. Asimismo, en forma paralela, avanzar en la negociación del acuerdo uE-Mercosur. Pimentel defendió la eliminación de todas las barreras para importaciones provenientes de Alemania e inversiones relacionadas con innovación tecnológica.

Por su parte, la presidenta de Brasil también afirmó que era necesario aumentar el comercio entre los dos países, ampliando el intercambio de bienes de mayor valor agregado. Ante posibles diferencias con la Argentina, la cNI sugirió que Brasil proponga al Mercosur alternativas que "flexibilicen" la capacidad de negociar acuerdos con otros bloques o países, para que "cada miembro camine según sus propios intereses".

El presidente de la Asociación de Comercio Exterior de Brasil, José Augusto de Castro, consideró también que el Mercosur "dejó de ser un bloque comercial para ser un acuerdo ideológico" y corre el riesgo de "quedar aislado del mundo" con la negociación anunciada por la UE y Estados Unidos, analizada más adelante.

En efecto, las cámaras de comercio exterior muestran preocupación por el avance de la Alianza Transpacífico y a partir de ello, presionan para que Brasil impulse tratados de liberalización comercial. José Augusto de Castro dijo recientemente que mientras los países de la zona del pacífico avanzan en su integración comercial con el mundo, el Mercosur solo liberaliza fronteras entre los países e incluso, el comercio con Argentina está disminuyen- do. "Hoy el Mercosur es más ideológico que comercial. Está volcado hacia adentro" (Frias, 2013). Por su parte, el director internacional de la Confederación de Agricultura y Pecuaria de Brasil ( $\mathrm{cNA}$ ), Thiago Masson, consideró que si fructifican las negociaciones entre Estados Unidos y la uE, los agricultores brasileños podrían perder terreno en ambos mercados (efe, 2013). Entre los objetivos declarados de la cNa figuran:

La unión del sector productor rural; la defensa del hombre de campo y de la economía agrícola; la valorización de la producción agrícola y la preservación del medio ambiente asociada al desarrollo agropecuario y de la producción de alimentos; la defensa del libre comercio de productos agropecuarios y agroindustriales; buscar y demostrar el correcto conocimiento de los problemas y soluciones apropiadas para las cuestiones de índole económica (cNA, 2013).

Actualmente, la cna preside la Federación de Asociaciones Rurales del Mercosur (Farm), de la que también forma parte la Sociedade Rural Brasileira (sRB). En el último documento elaborado por la $\mathrm{CNA}$ - Santiago de Chile, julio de 2012 - para presentar al Consejo de Ministros, se planteó su crítica al proteccionismo incluso dentro de la región, implicando su preocupación por el fracaso de la Ronda de Doha, su abierta oposición a la aplicación de derechos de exportación y su interés en promover el acuerdo con la Unión Europea, asimismo, los vínculos comerciales con China. Allí se afirma que:

... en el marco bilateral, si bien entendemos el impacto de la crisis económica actual, como bloque debemos priorizar el acuerdo con la Unión Europea. Lograr resultados concretos en este aspecto reforzaría, por un lado la institucionalidad del bloque, $y$ por otro, el acceso a un mercado de significativa relevancia para nuestra oferta exportable (FARM, 2012).

El 26 de septiembre de 2012, la Secretaría de Comercio Exterior del Ministerio de Desarrollo, Industria y Comercio lanzó la consulta 
pública respecto al acuerdo de libre comercio con la ue, para que el sector privado pudiera presentar una posición actualizada sobre la temática. El presidente de la cNI, Robson Braga de Andrade, afirmó que Brasil no tiene recelo de competir directamente con países europeos y que está dispuesto a discutir acuerdos de libre comercio con países de la ue y de otras regiones. Además, planteó que la finalidad es discutir las dificultades: las exigencias técnicas que piden los países europeos para los productos industriales brasileños y la doble tributación ha la que se ve sometido el intercambio de exportación e importación. Asimismo, señaló la necesidad de modificar el tipo de cambio, elevándolo aproximadamente a $\mathrm{R} \$ 2,47$ para equiparar la competitividad con las corrientes internacionales. Por su parte, Ricardo Roriz Coelho, vicepresidente de la FIEsP, se mostró preocupado por los altos costos y la baja competitividad, como condiciones para acompañar el crecimiento del mercado interno. El presidente de la Cámara de Comercio e Industria Brasil-Alemania, y de la empresa Volkswagen en Brasil, Thomas Schmall, solicitó incentivos específicos para la exportación (smabc, 2013).

Como se observó anteriormente, las corporaciones de productores rurales son más críticas de cualquier tipo de proteccionismo y por lo tanto, también más duras con la posición argentina. Un documento de la faemg - entidad que reúne a más de 400000 productores rurales del Estado de Minas Gerais- reproduce la posición del director general adjunto de Comercio de la Comisión Europea, João Aguiar Machado, quien afirmó durante el 6to. Encuentro Empresarial de la uE-Brasil realizado en la sede de la cNI, que tanto el gobierno brasileño como los empresarios están siendo "pasivos" respecto del proteccionismo argentino. El funcionario agregó: "entendemos que es preciso tratar con cuidado las relaciones con la vecindad, pero la ue tiene expectativa de que la comunidad empresaria brasileña haga oír más vivamente su voz" ante una política que la afecta. Por su parte, el presidente de la Unión Brasilera de Avicultura, representante de los productores de carne de pollo, Francisco Turra, consideró que "si [los argentinos] no desean participar, podemos avanzar nosotros, para que sea un acuerdo progresivo entre el Mercosur y la uE" (Valor Econômico, 2013).

Por otra parte, desde que Dilma Rousseff asumió el gobierno, realiza reuniones periódicas con empresarios, con el fin de evaluar la situación económica; asimismo, su gestión se ha caracterizado por dar una respuesta a las demandas provenientes del sector industrial. Por ejemplo, muchas de las principales medidas adoptadas, se vinculan con propuestas realizadas por la propia cNI (Winter, 2013). En 2010, Armando Monteiro Neto, vicepresidente de este lobby industrial, había señalado como problemas de la economía: el alto nivel de las tasas de interés, la excesiva apreciación del real $y$ el elevado costo de recursos como la electricidad. Las tres cuestiones han sido encaradas por el gobierno. Ocho meses después de asumir el poder, el Banco Central revirtió la anterior política de incremento de la tasa de interés, iniciando la reducción de la tasa referencial Selic, llevándola a su punto más bajo en octubre de 2012 (7,25\%). El gobierno presionó a los bancos privados para que recortaran sus tasas de crédito acompañando esa caída. Asimismo, intervino en el mercado de cambios y redujo las tarifas eléctricas, lo que provocó la oposición de las empresas extranjeras que se vieron perjudicadas con esa medida.

La principal política de incentivos aplicada frente al sector privado, ha sido la de reducir impuestos, no en forma generalizada sino sector por sector, en particular para industrias como las automotrices y las de electrodomésticos. De cualquier modo, el gobierno se caracteriza por la constante presentación de paquetes de estímulos de diferente orden.

En función de establecer mayor cercanía con el sector privado, Rousseff nombró presidente de la Cámara de Políticas de Gestión a Jorge Gerdau Johannpeter, presidente del Grupo Gerdau, una inmensa siderúrgica que opera en 14 países; es la mayor recicladora de América Latina y el segundo mayor fabricante mundial de acero para la construcción. Tiene cerca de 140000 accionistas y está ligada a la Bolsa de Valores de Sao Pablo, Nueva York y Madrid. 
Entre los empresarios aliados al gobierno de Rousseff se encuentra Marcelo Odebrech. Es el cEo y nieto del fundador de la empresa privada más grande de Brasil, un conglomerado que abarca construcción, ingeniería, energía, química, consultoría y petroquímica, asimismo, tiene operaciones $y$ negocios en gran parte del mundo. La empresa se comprometió a realizar una inversión de 17000 millones de reales durante 2013, es decir, un 30\% más que durante el 2012 (Monteiro, 2013).

Diferenciándose de los sectores de empresarios a los que se hizo referencia, Odebrech sentó su posición respecto al Mercosur y la Argentina, en una entrevista realizada a finales de 2012:

La Argentina siempre será uno de nuestros principales mercados [...]. Al Mercosur necesitamos profundizarlo. No está pasando. Lo peor que pasa hoy es que nos quedamos en la mitad. Empezamos en una zona aduanera, pero no migramos para el próximo paso. La solución para el Mercosur es profundizar el Mercosur. Enfatizo que la solución es más Mercosur. Tenemos que pedir más, no menos (Oviedo, 2012).

A pesar de esto, la inversión viene cayendo (en el año 2012, la inversión se situó en un $18,1 \%$ del PIB, un $6 \%$ inferior al 19,3\% registrado en 2011) (Instituto Brasileiro de Geografía e Estatística-IBGE, 2013), siendo otro elemento que impulsa al gobierno a atender aún más los reclamos de algunas corporaciones empresarias, como es el caso de los acuerdos de libre comercio.

\section{CONCLUSIÓN}

El gobierno de Dilma Rousseff se ha propuesto desde fines del año 2012, avanzar rápidamente en la negociación del acuerdo con la ue. Actualmente, la oposición brasileña critica al anterior gobierno de Lula da Silva, el haber sepultado los distintos tipos de acuerdos comerciales en danza, ya que según las estimaciones del Fondo Monetario Internacional, el comercio representa solo el
$25 \%$ de la economía brasileña, la proporción más baja de Latinoamérica detrás de Venezuela (52 \%), México (59\%) y Chile (71\%).

Sintetizando, el renovado esfuerzo en la vinculación comercial más estrecha con la UE se relaciona con: a) el temor a la reducción del superávit y posible déficit comercial; b) el anuncio de un futuro acuerdo entre Estados Unidos (competidor de productos agroexportables) $y$ la Unión Europea; c) la inminente exclusión de Brasil (y la permanencia de China e India) del Sistema General de Preferencias (sgp) de la ue; d) la proliferación de acuerdos económicos entre el viejo continente y los países del Pacífico y e) la crítica por parte de las organizaciones empresarias a los supuestos beneficios económicos del Mercosur para Brasil.

Creado en 1971, el sGP otorga un trato preferencial para colaborar con los países en desarrollo, a través del acceso a los grandes mercados. Motivados por la crisis que viven los países europeos y por la necesidad de obtener mayores recursos fiscales, la Unión Europea revisó el sGP de acuerdo a las nuevas clasificaciones del Banco Mundial (вм). A partir de 2014, serán excluidos del sGP, los países clasificados por el вм en los últimos tres años como países de renta media-alta, como es el caso de Argentina y Brasil. A pesar de ser uno de los mayores beneficiarios del sGP europeo, la dependencia de Brasil es menor a la de otros países emergentes. Por ejemplo, en el caso de la India, el 50\% de las exportaciones recibe un trato preferencial, mientras que en el caso brasileño, es alrededor del $12 \%$ de las ventas externas el que goza de ese trato preferencial. La eliminación de las preferencias alcanzará mayoritariamente a los productos manufacturados (tales como, productos químicos, autopartes y automóviles), lo que afectará el objetivo brasileño de diversificar su pauta exportadora incrementando la participación de productos de mayor valor agregado. El otro impacto relevante refiere a la modificación de las condiciones de competencia con otros países que compiten con Brasil por el mercado europeo; tal es el caso de China y la India, que permanecerán entre los países beneficiarios del SGP europeo. En este sentido, la modificación de las condiciones de competencia de Brasil con 
el resto de los países emergentes se constituye como el impacto más significativo para Brasil.

El avance de la Alianza Transpacífico constituye hoy otro impulso para que los industriales brasileños de la cNI $y$ la FIESP profundicen la embestida por la "flexibilización" del Mercosur en función de su promoción del acuerdo con la ue. "Necesitamos librarnos de esa camisa de fuerza, pues no vamos a concluir ningún acuerdo teniendo a Argentina $y$ Venezuela como socios", dijo a O Estado de Sao Pablo, Roberto Gianetti da Fonseca, Director de Comercio Exterior de la FIESP. Un documento presentado por la $\mathrm{cNI}$ en los primeros días de junio de 2012, denuncia que Brasil y el Mercosur están quedando afuera de las discusiones sobre grandes acuerdos comerciales (Mais, 2013). En la misma línea se posiciona actualmente, la Asociación Nacional de Fabricantes de Vehículos Automotores (Anfavea). Esas corporaciones industriales alegan que el gobierno está preso en su discurso ideológico y de ese modo, perjudica las exportaciones.

Aquella compleja combinación entre una política exterior que recuperó el discurso autonomista y una estrategia económica con resabios neoliberales se encuentra actualmente en una bisagra, atravesando una contradicción que los empresarios industriales presionan por definir (Varella, 2013).

Por último, los sucesos recientes que frustraron la visita de la presidenta Dilma Rousseff a los Estados Unidos, dan cuenta de que Brasil no puede descuidar su pertenencia a la región y que a pesar de la presión de los grupos económicos exportadores, la relación con el Mercosur y con la Argentina es fundamental para sustentar su proyecto económico industrial. El reciente desplazamiento y reemplazo del canciller Antonio Patriota ante el escándalo por el senador boliviano, así como, la afirmación de la presidenta Rousseff contra el espionaje realizado por los Estados Unidos en su gobierno y sus empresas, han provocado un posible quiebre en una tendencia que venía afirmándose. Ambos hechos, junto con las grandes movilizaciones sociales de los últimos meses, constituyen distintos tipos de alertas. Tanto en el ámbito estratégico político como económico, a Brasil no le conviene descuidar la relación con sus socios del Mercosur.

En cuanto al primer aspecto, el éxito de la política exterior brasileña también incluye la posibilidad de liderar el proceso de integración regional y su actual rol como representante del Cono Sur. Gran parte del interés depositado por la UE, se vincula con la percepción de Brasil como puerta de entrada a una cantidad de países de la región. En cuanto a los aspectos económicos, en el contexto de una balanza comercial que, como se ha visto, por primera vez modifica su tendencia superavitaria, observando la composición de las importaciones y exportaciones brasileñas, los países que actualmente sostienen el balance comercial de Brasil son China, Argentina (casi los únicos con variación positiva significativa en el último año) y los de la región de Medio Oriente. Especialmente, el caso argentino tiene relevancia porque ocupa el segundo lugar entre los destinos de las exportaciones brasileñas y las ventas de productos manufacturados representan el 91\% del total de lo exportado.

CUADRO 2

BRASIL: EXPORTACIONES A ARGENTINA POR VALOR AGREGADO 2012

\begin{tabular}{lcc}
\hline & MILES DE & \\
& MILLONES & PARTICI- \\
DE DÓLARES & PACIÓN \% \\
\hline Básicos & 1,1 & 6,2 \\
Semimanufacturados & 0,5 & 2,7 \\
Manufacturados & 16,4 & 91,0 \\
Transacciones especiales & 0,0 & 0,2 \\
\hline TOTAL & 18,0 & 100,0 \\
\hline
\end{tabular}

Fuente: Elaboración propia a partir de datos de SECEXMDIC, 2012.

Lo anterior, sin tener en cuenta las inversiones que tiene Brasil en ese país, lo que hace que toda otra línea de grandes empresarios nacionales se distancie de las posiciones de la FIEsP o la cNr. Por lo tanto, el gigante del sur deberá tener en cuenta las condiciones del acuerdo con 
la Unión Europea, a la hora de negociar con el resto de los países del Mercosur.

El escenario reciente muestra señales en esa línea. Luego de algunos meses de tensión, Argentina y Brasil parecen retomar la senda del trabajo conjunto, para presentar una propuesta que potencie sus modelos económicos de desarrollo.

\section{BIBLIOGRAFÍA}

REVISTAS

Bresser Pereira, Luiz Carlos. "A tendência à sobre apreciação da taxa de câmbio". Econômica 11 (1). 2009: 7-30.

Bresser Pereira, Luiz Carlos. "Economia do desenvolvimento. Do antigo ao novo desenvolvimentismo na América Latina". Desenvolvimento econômico e crise. Ensaios em comemoração aos oitenta anos de Maria da Conceição Tavares. Luiz Carlos Prado (org.). Rio de Janeiro, Brasil: Contraponto, 2012.

Cason, J. y Power, T. "Presidentialization, pluralization, and the rollback of Itamaraty: explaining change in Brazilian foreign policy making from Cardoso to Lula". International Political Science Review 30. 2009: 117-140. [Revista digital]. En: <http://ips.sagepub. com/content/30/2/117.full.pdf+html> [consultado el 15 de mayo de 2013].

De Almeida, Paulo Roberto. "O Brasil como ator regional e como emergente global: estratégias de política externa e impactos na nova ordem internacional". Cena Internacional 9 (1).Brasil. Instituto de Relações Internacionais da UnB, 2007: 7-36.

Estrella Faria, Luiz Augusto. "Las negociaciones comerciales de Brasil: escenarios, agendas e intereses". Revista del Sur 166. Red del Tercer Mundo. Julio-agosto 2006. [Revista digital]. En: <http://old.redtercermundo.org. uy/revista_del_sur/texto_completo. php?id=3090> [consultado el 18 de septiembre de 2013].

Giaccaglia, Clarisa. "La influencia de los actores domésticos en la política exterior brasileña durante el gobierno de Lula da Silva”. Revista Confines 6 (12). Instituto Tecnológico de Monterrey. Agostodiciembre 2010. [Revista digital]. En: <http://web2.mty.itesm.mx/temporal/ confines/articulos12/GiaccagliaC.pdf> [consultado el 14 de mayo de 2013].

Gomes Saraiva, Miriam y Valença, Marcelo. "Brasil: potencia regional con intereses globales". Revista Diálogo Político 4. Fundación Konrad Adenauer, 2011: 99-119.

Hirst, Monica; Soares de Lima, Maria Regina y Pinheiro, Leticia. "A politica externa brasileira em tempos de novos horizontes e desafíos". Nueva Sociedad. Luzes e sombras do Brasil atual. Friedrich Ebert Stiftung, 2010: 22-41.

Malamud, Andrés. "La Unión Europea, del interregionalismo con América Latina a la asociación estratégica con Brasil". Revista CIDOB d'afers internacionals 97-98. сіDOB, abril 2012: 219-230.

Malamud, Andrés. "La política externa de Dilma Rousseff: ¿menos de 10 mismo?". Iberoamericana. América Latina-España-Portugal 41. Editorial Iberoamericana-Vervuert, 2011: 174-179.

\section{TEXTOS ELECTRÓNICOS}

Alvarenga, Darlan. "Protecionismo no Brasil 'seria como dar tiro no pé', diz Pimentel". O Globo. 13 de mayo 2013. En: <http:// g1.globo.com/economia/noticia/2013/05/ protecionismo-no-brasil-seria-comodar-tiro-no-pe-diz-pimentel.html> [consultado el 25 de agosto de 2013].

Butler, Desmond y Melvin, Don. "Disputas agrícolas amenazan negociaciones EE.UUUE". PáginaNoticias. 23 de marzo de 2013. En: <http://www.paginanoticias. com/n/Economia/-74vqkxkpn/ Disputas-agr\%C3\%ADcolas-amenazannegociaciones-EEUU-UE.htm> [consultado el 25 de agosto de 2013].

Confederación de agricultura y pecuaria de Brasil (CNA). Página principal. S. f. En: $<$ http://www.farmercosur.org/index. php/es/institucional/-miembros/cna> [consultado el 23 de septiembre de 2013]. 
Comisión Europea. "Communication from the Commission to the Council and the European Parliament. Towards an EU-Brazil strategic partnership"”. Commission of the European Communities 281. 30 de mayo de 2007. En: <http://eur-lex.europa.eu/ LexUriServ-/LexUriServ.do?uri=com:20 07:0281:FIN:EN:PDF> [consultado el 24 de mayo de 2013].

Comunidad de Estados Latinoamericanos y Caribeños-Cumbre Unión Europea (CELAC-CUE). Documento final de la lera. Cumbre CELAC-Unión Europea. Santiago de Chile, 26 y 27 de enero de 2013. En: $<$ http://www.europarl.europa.eu/intcoop/ eurolat/key_documents/summits_ eu_alc/1_celac-ue_2013/santiago_ declaration_es.pdf> [consultado el $16 \mathrm{de}$ septiembre de 2013].

DefensaNet. Sem acordos, Mercosul vai perder espaço, diz Patriota. 19 de setiembre de 2013. En: http://www.defesanet.com.br/ geopolitica/noticia/7809/Sem-acordos-Mercosul-vai-perder-espaco--diz-Patriota [consultado el 25 de septiembre de 2013].

EFE. "Argentina quiere que la propuesta de Mercosur a la UE reconozca asimetrías". Infolatam, 27 de enero de 2013. En: <http://www.infolatam.com/2013/01/27/ argentina-quiere-que-la-propuesta-demercosur-a-la-ue-reconozca-asimetrias> [consultado el 25 de agosto de 2013].

EFE. "Expertos alertan de impacto de negociación UE-EE.UU en Mercosur". El Espectador. 15 de febrero de 2013. En: <http://www.elespectador.com/noticias/ economia/articulo-405000-expertosalertan-de-impacto-de-negociacion-ueeeuu-mercosur $>$ [consultado el 16 de julio de 2013].

Federación de Asociaciones Rurales del Mercosur (FARM). Documento final de la XXIII Reunión Ordinaria del Consejo Agropecuario del Sur (CAS). Santiago de Chile, 25 de julio de 2012. En: <http:// www.farmercosur.org/documentos/farm DocumentoxxIII\%20CAs\%20FINAL_3.pdf [consultado el 23 de septiembre de 2013].
Federación de Industrias del Estado de Sao Pablo (FIESP). O impacto do sistema geral de preferencias (SGP) europeu nas exportaçoes brasileiras. FIESP, 2011. En: <http://www.fiesp.com.br/indicespesquisas-e-publicacoes/o-impactodo-sistema-geral-de-preferencia-sgpeuropeu-nas-exportacoes-brasileiras> [consultado el 16 de junio de 2013].

Frias, María Cristina. "Aliança Pacífico preocupa exportadores e importadores". Folha de São Paulo. 31 de mayo de 2013. En: <http://www1.folha.uol.com.br/colunas/ mercadoaberto/2013/05/1287547-aliancapacifico-preocupa-exportadores-eimportadores. shtml> [consultado el 28 de agosto de 2013].

Guimarães, Marina. "Argentina discute proposta de negociação Mercosul- UE". Grupo Estadão. 16 de setiembre de 2013. En: <http://www.estadao.com.br/ noticias/ nacional,argentina-discuteproposta-de-negociacao-mercosulue,1075360,0.htm> [consultado el 3 de octubre de 2013].

Instituto Brasileiro de Geografia e Estatística (IBGE). "En 2012, PIB crece el 0,9\% $y$ totaliza R \$ 4,403 billones". IBGE, $1^{\circ}$ de marzo de 2013. En: <http:// saladeimprensa.ibge.gov.br/ es/ noticias? $v i e w=$ noticia $\& i d=1 \&$ busca $=1$ \&idnoticia $=2329>$ [consultado el 05 de agosto de 2013].

Lavopa, Federico y Dalle, Demian. ¿Hay vida después del SGP? Implicancias de la posible exclusión de Argentina de los sistemas generalizados de preferencias de Estados Unidos y la Unión Europea. Argentina: Cátedra Organización Mundial del Comercio - Facultad Latinoamericana de Ciencias Sociales (oMC-FLACSO), 2012. En: <http:// catedraomc.flacso.org.ar/wp-content/ uploads/2012/02/Anexo-1_sGP.pdf> [consultado el 15 de agosto de 2013].

Mais, Leia. "CNI diz que Brasil e Mercosul se isolam do comércio mundial". Exame. 4 de junio de 2013. En: <http://exame.abril. com.br/brasil/noticias/cni-diz-que-brasil- 
e-mercosul-se-isolam-do-comerciomundial> [consultado el 10 de agosto 2013].

Ministério das Relações Exteriores, Balanço. Política Externa 2003/2010. Reforma da Governança Global - IBAS. 2012. En: <http://www.itamaraty.gov.br/temas/ balanco-de-politica-externa-20032010/3.1.3-reforma-da-governancaglobal-ibas $>$ [consultado el 16 de septiembre de 2013].

Monteiro, Tânia. "Após reunião com Dilma, Odebrecht anuncia investimento de $\mathrm{R} \$$ 17 bi em 2013". O Estado. 10 de enero 2013. En: <http://economia.estadao.com. $\mathrm{br} /$ noticias/negocios-industria,aposreuniao-com-dilma-odebrechtanuncia-investimento-de-r-17-biem-2013,140308,0.htm> [consultado el 24 de agosto de 2013].

None, Jeremy. "UE-MERCOSUR: vers un accord d'association subrégional? Bilan, enjeux et perspectives". Diplo web. 2012. En: $<$ http://www.diploweb.com/UE-MERCosuRvers-un-accord-d.html> [consultado el 23 de septiembre de 2013].

Oviedo, Jorge. "El Mercosur no pasa por un buen momento". La Nación. 24 de noviembre de 2012. En: <http://www. lanacion.com.ar/1529772-marceloodebrecht-el-mercosur-no-pasapor-unbuen-momento $>$ [consultado el 16 de julio de 2013].

Peña, Félix. ¿Es factible que en la Cumbre de Madrid se relancen las negociaciones UE-Mercosur? Madrid: Real Instituto Elcan, 9 de abril de 2010. En: <http:// www.realinstitutoelcano.org/wps/portal/ rielcano/contenido?WCM_GLOBAL CONTEXT=/elcano/elcano_es/zonas_es/ america+latina/ari65-2010> [consultado el 16 de septiembre de 2013].

Portal Vermelho. "Argentina defende que Mercosul feche acordoscom a UniãoEuropeia”. Portal Vermelho. 24 de setiembre de 2013. En: <http:// www.vermelho.org.br/noticia.php?id_ noticia $=224974 \&$ id_secao $=7>$ [consultado el 3 de octubre de 2013].

Rodríguez Iglesias, Ana Isabel. La Asociación Estratégica UE - Brasil Retórica y Pragmatismo en las Relaciones EuroBrasileñas 36 (1). Madrid Instituto Universitario de Estudios EuropeosUniversidad San Pablo: CEU Ediciones, 2010. En: <http://www.idee.ceu.es/ Portals/0/Publicaciones/La-AsociacionEstratégica-UE-Brasil-1.pdf> [consultado el 2 de mayo de 2013].

Sindicato dos Metalúrgicos do ABC (SMABC). "Indústria diz que Brasil não é protecionista, mas reclama de câmbio". SMABC, 14 de mayo 2013. En <http:// www.smabc.org.br/smabc/materia. asp?id_CON=31982> [consultado el 25 de septiembre de 2013].

Valor Econômico. "UE cobra firmeza do Brasil emreação a barreira argentina”. Valor Econômico. Brasil. 25 de enero de 2013. En <http://www.valor.com.br/ brasil/2982048/ue-cobra-firmeza-dobrasil-em-reacao-barreira-argentina> [consultado el 25 de septiembre de 2013].

Varella, João. "Preso no Mercosul, Brasil só assiste Aliança do Pacífico crescer". El Economista. Brasil. 3 de junio de 2013. En: <http://www.eleconomistaamerica. com.br/ economia-eAmbrasil/ noticias/4878780/06/13/Preso-noMercosul-Brasil-so-assiste-Aliana-doPacifico-crescer-.html> [consultado el 15 de septiembre de 2013].

Winter, Brian. "Presidenta de Brasil lucha para seducir al sector empresario". Chicago Tribune. Sao Paulo, Brasil. 4 de marzo de 2013. En: <http://articles.chicagotribune. com/2013-03-04/news/sns-rt-brasilrousseff-fotol1n0bsh1s-20130304_1_ asuntos-como-la-presidenta-los-1-deresempresariales $>$ [consultado el 19 de agosto de 2013].

Zanatta, Mauro y Dantas, Iuri. "Oferta de acordó com a UE prevê corte de tarifas 
para $75 \%$ dos productos". Grupo Estadão. Brasil, 3 de setiembre de 2013. En: <http://economia.estadao.com.br/ noticias/economia-internacional,of... com-a-ue-preve-corte-de-tarifas- para-75-dos-produtos, $163734,0$. htm> [consultado el 3 de octubre de 2013].

Fecha de ingreso: 04/10/2013 Fecha de aprobación: 12/12/2013 
